\title{
BMJ Global Health Modelling costs of community-based HIV self-testing programmes in Southern Africa at scale: an econometric cost function analysis across five countries
}

Marc d'Elbée, ${ }^{1}$ Gabriela B Gomez, ${ }^{1}$ Linda Alinafe Sande (D) ,1,2 Lawrence Mwenge, ${ }^{3}$ Collin Mangenah (D) , ${ }^{4}$ Cheryl Johnson, ${ }^{5}$ Graham F Medley, ${ }^{1}$ Melissa Neuman (D) , Karin Hatzold, ${ }^{7}$ Elizabeth Lucy Corbett, ${ }^{2,8}$ Gesine Meyer-Rath, ${ }^{9,10}$

Fern Terris-Prestholt ${ }^{1,11}$

To cite: d'Elbée M, Gomez GB, Sande LA, et al. Modelling costs of community-based HIV self-testing programmes in Southern Africa at scale: an econometric cost function analysis across five countries. BMJ Global Health 2021;6:e005554. doi:10.1136/ bmjgh-2021-005554

Handling editor Edwine Barasa

- Additional material is published online only. To view, please visit the journal online (http://dx.doi.org/10.1136/ bmjgh-2021-005554).

Received 1 March 2021 Accepted 25 May 2021
Check for updates

(c) World Health Organization 2021. Licensee BMJ.

For numbered affiliations see end of article.

Correspondence to Dr Marc d'Elbée;

marc.delbee@lshtm.ac.uk

\section{ABSTRACT}

Background Following success demonstrated with the HIV Self-Testing AfRica Initiative, HIV self-testing (HIVST) is being added to national HIV testing strategies in Southern Africa. An analysis of the costs of scaling up HIVST is needed to inform national plans, but there is a dearth of evidence on methods for forecasting costs at scale from pilot projects. Econometric cost functions (ECFs) apply statistical inference to predict costs; however, we often do not have the luxury of collecting large amounts of location-specific data. We fit an ECF to identify key drivers of costs, then use a simpler model to guide cost projections at scale.

Methods We estimated the full economic costs of community-based HIVST distribution in 92 locales across Malawi, Zambia, Zimbabwe, South Africa and Lesotho between June 2016 and June 2019. We fitted a cost function with determinants related to scale, locales organisational and environmental characteristics, target populations, and per capita Growth Domestic Product (GDP). We used models differing in data intensity to predict costs at scale. We compared predicted estimates with scale-up costs in Lesotho observed over a 2-year period.

Results The scale of distribution, type of communitybased intervention, percentage of kits distributed to men, distance from implementer's warehouse and per capita GDP predicted average costs per HIVST kit distributed. Our model simplification approach showed that a parsimonious model could predict costs without losing accuracy. Overall, ECF showed a good predictive capacity, that is, forecast costs were close to observed costs. However, at larger scale, variations of programme efficiency over time (number of kits distributed per agent monthly) could potentially influence cost predictions.

Discussion Our empirical cost function can inform community-based HIVST scale-up in Southern African countries. Our findings suggest that a parsimonious ECF can be used to forecast costs at scale in the context of financial planning and budgeting.

\section{WHAT IS ALREADY KNOWN}

$\Rightarrow$ Following success demonstrated with the HIV SelfTesting AfRica) Initiative, HIV self-testing is being added to national HIV testing strategies in Southern Africa.

$\Rightarrow$ Community-based models delivering HIV self-testing either at people's homes or within the community setting with mobile outreach are a convenient approach for reaching undertested groups such as young people (16-25 years old) and men.

$\Rightarrow$ There is little guidance or empirical evidence on methods for forecasting costs at scale for programming and planning.

\section{WHAT ARE THE NEW FINDINGS}

$\Rightarrow$ Our study developed an econometric cost function for scaling up community-based HIV self-testing programmes for the general population in Southern Africa, using data from five countries.

$\Rightarrow$ Our model simplification approach showed that we could use a more parsimonious model, including scale, type of community-based intervention, percentage of men reached by the programme, distance from implementer's warehouse and per capita Growth Domestic Product, to predict costs without significantly losing accuracy.

\section{WHAT DO THE NEW FINDINGS IMPLY}

$\Rightarrow$ The extrapolation of cost predictions to inform community-based HIV self-testing scale-up in Southern African countries is possible with our empirical cost function.

$\Rightarrow$ Our analysis adds to the literature on the trade-off between simplicity versus accuracy in cost projection methods.

\section{INTRODUCTION}

The HIV burden remains concentrated in Southern Africa, with estimated adult prevalence ranging between $10.6 \%$ in Malawi and $25.6 \%$ in Lesotho in $2018 .^{1}$ Expanding access 
to HIV testing services (HTS) and ensuring linkage to prevention or timely antiretroviral therapy initiation for people living with HIV is vital to achieving epidemic control. HIV self-testing (HIVST) is an additional testing modality where an individual collects his or her own oral fluid or blood sample, conducts the test and interprets results. HIVST has increased the uptake and frequency of testing among individuals who would not test otherwise. ${ }^{23}$ The Unitaid-funded Self-Testing AfRica (STAR) Initiative led by Population Services International (PSI) started implementing HIVST delivery models in southern Africa in 2016. ${ }^{4}$ Many HIVST distribution models were evaluated, including community-based, workplace, public and private sector facility-based primary distribution strategies, and secondary distribution strategies to sexual partners and peers among key populations. ${ }^{5}$

Community-based models delivering HIVST either at people's homes or within the community setting with mobile outreach were shown to be a convenient approach for reaching undertested groups such as young people (16-25 years old) and men. ${ }^{6-10}$ Although community-based approaches are expensive from a provider perspective, they decrease users' costs in accessing HIV testing, in particular among working men whose time might be more expensive..$^{911} 12$ Following the success demonstrated in the STAR Initiative, the Lesotho Ministry of Health added HIVST to its revised national HTS strategic plan for 2018-2023. ${ }^{13}$ An analysis of the costs of scaling-up HIVST (increasing the provision of HIVST kits) was needed by country planners to inform the HIVST national scale-up plans and budget in Lesotho. However, there is little guidance or empirical evidence on methods for projecting costs at scale for programming and planning. ${ }^{14} 15$

Cost functions can be derived from a production function to estimate the total cost of production given a specific output produced. The simplest cost function multiplies a single unit cost by a quantity-the commonly used 'simple cost multiplier' (SCM). It is a practical costing method used for high level budgeting. ${ }^{15}$ Accounting cost functions (ACFs) identify all the cost inputs to a production process (equipment, personnel, etc) over a defined costing period (usually 1 year) and categorise them as fixed, semi-fixed or variable costs in the short run or all variable in the long run. ${ }^{14-17}$ Econometric cost functions (ECF) do not follow the production process but rather apply statistical inference to predict costs. The challenge of ECF is to reflect the complexity of real-world production process with a mathematical model of inputs and outputs. ${ }^{14}{ }^{16}$ In most studies, we do not have the luxury of collecting large amounts of location-specific cost data, and applications of ECF for cost predictions are rare ${ }^{14}{ }^{18}$ In the absence of detailed data, SCM is commonly used.

This study aims to fit an ECF to estimate the cost drivers of the community-based HIVST programmes in Southern Africa using data from Malawi, Zambia, Zimbabwe and South Africa. We then inform the use of
ECF to predict costs at scale by comparing ECF models with different level of data requirements. Finally, we assess the validity of our empirical ECF by comparing projected costs with observed costs at scale in Lesotho. We select Lesotho as our case study because we conducted in this country a longitudinal microcosting analysis of HIVST scale-up from a real-world intervention over 2 years of implementation. ${ }^{19}$

\section{METHODS}

\section{Setting: data sources}

We estimated the full economic costs of communitybased HIVST distribution in 92 sites across Malawi, Zambia, Zimbabwe, South Africa and Lesotho (table 1). ${ }^{12} 1920$ We collaboratively developed cost analysis methods following standard guidelines and analysed data, ensuring consistency of methods across countries. ${ }^{1521}$ Programme expenditures supplemented by on-site observation and monitoring and evaluation data were used to estimate HIVST distribution costs. ${ }^{22}$ Costing studies in Malawi, Zambia and Zimbabwe were conducted as part of larger randomised controlled trials. ${ }^{12}$ We also conducted time and motion studies. Cost data collection and analysis methods are described in detail elsewhere. ${ }^{12} 2324$ Some variations of the 'community-based' intervention were observed between countries and are described in online supplemental appendix text S1. For resources shared across different services, models or levels, we allocated expenditure using allocation factors summarised in online supplemental appendix table S1. Costs were adjusted for inflation using each country's Consumer Price Index and presented in 2019 US $\$ .^{15} 25$

For cost determinants (or cost drivers) presented in table 2, data on scale, number of HIVST distributors per site, efficiency, type of community-based intervention, percentages of HIVST kits distributed to men and to those who never tested for HIV were collected through the PSI monitoring and evaluation programme. Distance between distribution site and PSI headquarters, size of catchment population, HTS costs and positivity rates at nearby health facilities, per capita Growth Domestic Product (GDP) in 2019 US\$, were collected as part of the STAR costing studies. ${ }^{124}$

\section{Study timelines}

Cost data were collected between June 2016 and June 2019 across all countries (figure 1). For the analysis of observed costs at scale in Lesotho, costs were collected between August 2017 and April 2019 (17 months) in five districts (Berea, Leribe, Mafeteng, Maseru and Mohale's Hoek) where HIVST kits were distributed. We observed three scale-up phases of approximately 6 months each in Lesotho (period 1: December 2017April 2018; period 2: May 2018-October 2018; and period 3: November 2018-April 2019). 
Table 1 Overview of interventions by countries

\begin{tabular}{|c|c|c|c|c|c|c|}
\hline & Malawi & Zambia & Zimbabwe & South Africa & Lesotho & Source \\
\hline $\begin{array}{l}\text { Per capita Gross Domestic } \\
\text { Product (2019 US\$) }\end{array}$ & $\$ 412$ & $\$ 1305$ & $\$ 1464$ & $\$ 6001$ & $\$ 1118$ & 52 \\
\hline $\begin{array}{l}\text { National HIV prevalence } \\
\text { among adults } 15-59 \text { years } \\
(\%)-2018\end{array}$ & 10.6 & 12.0 & 14.6 & 20.4 & 25.6 & $53-57$ \\
\hline Intervention district & $\begin{array}{l}\text { Blantyre, } \\
\text { Machinga, } \\
\text { Mwanza and } \\
\text { Neno }\end{array}$ & $\begin{array}{l}\text { Choma, Lusaka, } \\
\text { Ndola and } \\
\text { Kapiri }\end{array}$ & $\begin{array}{l}\text { Mberengwa, } \\
\text { Buhera Masvingo, } \\
\text { Chivi, Gweru, } \\
\text { Bulilima, Gutu and } \\
\text { Mazowe }\end{array}$ & $\begin{array}{l}\text { City of Tshwane, } \\
\text { City of } \\
\text { Johannesburg }\end{array}$ & $\begin{array}{l}\text { Maseru, Berea, } \\
\text { Leribe } \\
\text { Mohale and } \\
\text { Mafeteng }\end{array}$ & 58 \\
\hline Definition of site & $\begin{array}{l}\text { Catchment area } \\
\text { of a rural public } \\
\text { primary health } \\
\text { clinic }\end{array}$ & $\begin{array}{l}\text { Catchment area } \\
\text { of a rural public } \\
\text { primary health } \\
\text { clinic }\end{array}$ & $\begin{array}{l}\text { Ward } \\
\text { (subdivision of a } \\
\text { district) }\end{array}$ & District & $\begin{array}{l}\text { Catchment area } \\
\text { of a PSI fixed } \\
\text { site }(\sim 1 \text { per } \\
\text { district), that is, } \\
\text { a district and } \\
\text { across all five } \\
\text { districts, for } \\
\text { each period } 1-3\end{array}$ & 12 \\
\hline Number of sites & 11 & 16 & 44 & 3 & 18 & 58 \\
\hline $\begin{array}{l}\text { Location: rural; urban or } \\
\text { periurban }\end{array}$ & $11 ; 0$ & $8 ; 8$ & $44 ; 0$ & $0 ; 3$ & $4 ; 1$ & 58 \\
\hline Analysis period & $\begin{array}{l}\text { June 2016- } \\
\text { May } 2017 \text { (12 } \\
\text { months) }\end{array}$ & $\begin{array}{l}\text { June 2016- } \\
\text { May } 2017 \text { (12 } \\
\text { months) }\end{array}$ & $\begin{array}{l}\text { June 2016-May } \\
2017 \text { (12 months) }\end{array}$ & $\begin{array}{l}\text { June } 2018 \text {-June } \\
2019 \text { (13 months) }\end{array}$ & $\begin{array}{l}\text { August 2017- } \\
\text { April } 2019 \text { (17 } \\
\text { months) }\end{array}$ & 58 \\
\hline $\begin{array}{l}\text { Total number of HIVST } \\
\text { kits distributed in included } \\
\text { sites during observation } \\
\text { period }\end{array}$ & 152671 & 103589 & 92559 & 154111 & 51676 & 121958 \\
\hline
\end{tabular}

\section{Econometric analysis}

Econometric model specification using data from Malawi, Zambia, Zimbabwe and South Africa

We start our analysis with the conventional cost function where total costs are a function of quantity and prices. ${ }^{17}$ We use a linear regression approach (Ordinary Least Squares) and use average cost per HIVST kit distributed (arithmetic mean) as the dependent variable. ${ }^{26} \mathrm{We}$ use average costs instead of total costs as our sample is composed of sites at various administrative levels between countries (district and catchment area of health facility), thus making comparison more intuitive and because the unit of output (HIVST kits distributed) is clearly defined (Equation 1). We included PSI central costs (country and regional offices) in the average cost estimates to allow for comparison with observed costs at scale. Because the cost data were highly skewed to the right with a heavy tail, we log-transformed the dependent variable. ${ }^{26}$

Cost determinants were selected based on the economic theory of production function, through programme observation, and the literature on cost functions for HIV care services. ${ }^{14}{ }^{16}$ 27-39 Cost drivers' description, expected effect on costs and justification for inclusion in the model are presented in table 2, following Lépine and colleagues, ${ }^{35}$ approach for the categorisation of determinants. We used multiple imputation for missing data; although overall missingness was low, mean and standard deviation (SD) were comparable before/after imputation. We checked model robustness with the addition/removal of single regressors. The cost function was fitted using the $\mathrm{R}$ package. ${ }^{40}$

Equation 1

$$
\begin{aligned}
& C=\sum_{k} A C_{k} \cdot Q_{k} \text { with } \log \left(A C_{k}\right)=\beta_{0}+\beta_{1} * \text { Scale }_{k}+\beta_{2} * \text { Scale }_{k}^{2}+\beta_{3} * \text { Scale }_{k}^{3}+ \\
& \beta_{4} * \text { Distributor_site }_{k}+\beta_{5} * \text { Campaign }_{k}+\beta_{6} * \log \left(\text { Efficiency }_{k}\right)+\beta_{7} * \text { Perc_men }_{k}+ \\
& \beta_{8} * \text { Perc_never_tested }_{k}+\beta_{9} * \text { Distance }_{k}+\beta_{10} * \text { Population }_{k}+\beta_{11} * \text { Positivity }_{k}+ \\
& \beta_{12} * \text { Cost_facility }{ }_{k}+\beta_{13} * \text { Price_level }_{k}
\end{aligned}
$$

Where:

C: total programme cost $\mathrm{k}$ : level of analysis: district, catchment area of health facility.

$\log \left(\mathrm{AC}_{\mathrm{k}}\right)$ : natural logarithm of the average cost per scale variable $Q_{k}$ for level $k$.

Scale: average number of HIVST kits distributed per month.

Distributor_site: average number of distributors per site.

Campaign: type of intervention (campaign style vs fixed distributors).

$\log$ (Efficiency): natural logarithm of the number of HIVST kits distributed per agent monthly. 
Table 2 Variable categories, description, expected effect on costs and justification

\begin{tabular}{|c|c|c|c|c|c|}
\hline Variable category & Variable name & Description & $\begin{array}{l}\text { Expected } \\
\text { effect on } \\
\text { costs }\end{array}$ & Justification & Source \\
\hline Dependent variable & $\begin{array}{l}\text { Average costs per HIVST } \\
\text { kit distributed including } \\
\text { central costs }\end{array}$ & $\begin{array}{l}\text { Unit costs per HIVST kit } \\
\text { distributed including in- } \\
\text { country central costs and } \\
\text { start-up costs in } 2019 \\
\text { US\$ }\end{array}$ & NA & NA & 12 \\
\hline Quantities & Scale & $\begin{array}{l}\text { Number of HIVST kit } \\
\text { distributed by site during } \\
\text { the observation period }\end{array}$ & \pm & (Dis)Economies of scale & PSI \\
\hline \multirow[t]{3}{*}{$\begin{array}{l}\text { Site organisational } \\
\text { characteristics }\end{array}$} & HIVST distributors & $\begin{array}{l}\text { Number of full time } \\
\text { equivalent HIVST } \\
\text { distributor in each site }\end{array}$ & \pm & $\begin{array}{l}\text { Increase your coverage and \# of } \\
\text { HIVST kits distributed (so lower } \\
\text { average costs per kit distributed), } \\
\text { but also increase personnel costs }\end{array}$ & PSI \\
\hline & Campaign style & $\begin{array}{l}\text { Variable coded } 1 \text { if } \\
\text { the same distributors } \\
\text { travel from sites to } \\
\text { sites (campaign style } \\
\text { distribution) or } 0 \text { if they } \\
\text { live within the community }\end{array}$ & + & $\begin{array}{l}\text { In some countries, HIVST kits } \\
\text { distribution was more conservative } \\
\text { and restricted by campaign duration } \\
\text { in each site, so this approach could } \\
\text { drive costs higher due to lower } \\
\text { volumes of kits distributed and } \\
\text { travel costs }\end{array}$ & PSI \\
\hline & Efficiency & $\begin{array}{l}\text { Number of HIVST kits } \\
\text { distributed per agent per } \\
\text { month }\end{array}$ & - & $\begin{array}{l}\text { The higher the number of HIVST } \\
\text { kits distributed per agent, the more } \\
\text { efficient they are and the lower is the } \\
\text { cost per kit distributed }\end{array}$ & PSI \\
\hline \multirow[t]{2}{*}{$\begin{array}{l}\text { Characteristics of } \\
\text { population targeted }\end{array}$} & $\begin{array}{l}\% \text { HIVST kits distributed } \\
\text { to men }\end{array}$ & $\begin{array}{l}\text { Number of kits distributed } \\
\text { to men - also measure if } \\
\text { programme is targeting } \\
\text { well (proxy for quality) }\end{array}$ & + & $\begin{array}{l}\text { Men might be harder to reach and to } \\
\text { convince to take a kit, might lead to } \\
\text { higher costs of provision }\end{array}$ & PSI \\
\hline & $\%$ never tested for HIV & $\begin{array}{l}\% \text { of people who never } \\
\text { tested for HIV }\end{array}$ & - & $\begin{array}{l}\text { Higher knowledge of HIV status } \\
\text { might lead to lower demand for } \\
\text { testing, including HIVST, leading } \\
\text { to increased average cost per kit } \\
\text { distributed }\end{array}$ & $\begin{array}{l}\text { STAR } \\
\text { household } \\
\text { surveys }\end{array}$ \\
\hline \multirow[t]{4}{*}{$\begin{array}{l}\text { Environmental } \\
\text { characteristics }\end{array}$} & Distance & $\begin{array}{l}\text { Distance from central } \\
\text { warehouse to site in } \\
\text { kilometres }\end{array}$ & + & $\begin{array}{l}\text { Longer distance from the PSI } \\
\text { headquarters and warehouse } \\
\text { might lead to high costs of service } \\
\text { provision }\end{array}$ & $\begin{array}{l}\text { PSI, Google } \\
\text { Maps }\end{array}$ \\
\hline & Catchment population & $\begin{array}{l}\text { Size of the catchment } \\
\text { population of the site } \\
\text { regardless of eligibility }\end{array}$ & - & $\begin{array}{l}\text { Number of potential HIVST } \\
\text { recipients affect levels of distribution } \\
\text { potentially leading to economies of } \\
\text { scale }\end{array}$ & $\begin{array}{l}\text { PSI, Ministry } \\
\text { of Health }\end{array}$ \\
\hline & Positivity at health facility & $\begin{array}{l}\text { Annual new HIV positive } \\
\text { identified over total tested } \\
\text { at nearby health facility } \\
\text { (positivity rate) }\end{array}$ & + & $\begin{array}{l}\text { If the health facilities experience } \\
\text { high positivity rates, the demand } \\
\text { for HIVST might be lower leading } \\
\text { to increased average costs (higher } \\
\text { costs to reach the last \% of target } \\
\text { population) }\end{array}$ & $\begin{array}{l}\text { PSI, Ministry } \\
\text { of Health }\end{array}$ \\
\hline & $\begin{array}{l}\text { HTS average cost at } \\
\text { health facility }\end{array}$ & $\begin{array}{l}\text { Average cost per person } \\
\text { tested with HTS at the } \\
\text { nearest health facility }\end{array}$ & + & $\begin{array}{l}\text { Although not a determinant, a } \\
\text { significant correlation might suggest } \\
\text { the effect of other unobserved } \\
\text { environmental characteristics on } \\
\text { costs }\end{array}$ & 1224 \\
\hline Input price level & Price level & $\begin{array}{l}\text { Per capita Growth } \\
\text { Domestic Product in } 2019 \\
\text { US\$ }\end{array}$ & + & $\begin{array}{l}\text { Proxy for input price level variation } \\
\text { across countries }\end{array}$ & 52 \\
\hline
\end{tabular}

HTS, HIV testing services; PSI, Population Services International; STAR, Self-Testing AfRica. 


\begin{tabular}{|c|}
\hline 2016 \\
\hline
\end{tabular}

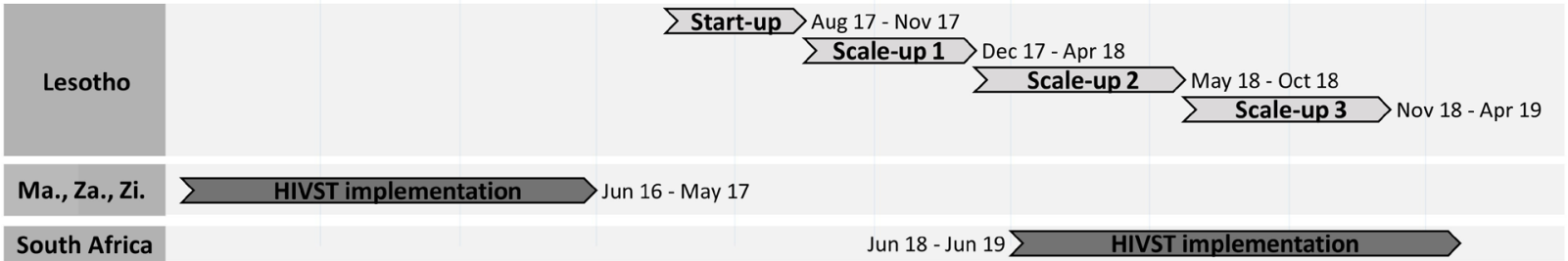

Data sources:

$\square$ Observed scale-up

$\square$ Econometric cost function

Figure 1 STAR costing period and data sources by country for each cost analysis. HIVST, HIV self-testing; MA, Malawi; STAR, HIVSelf-Testing AfRica; Za, Zambia; Zi, Zimbabwe.

Perc_men: percentage of HIVST kits distributed to men out of total distribution volumes.

Perc_never_tested: percentage of HIVST kits distributed to people who never tested before out of total distribution volumes.

Distance: distance of site from implementer's central warehouse (in kilometres).

Population: size of total population at the site.

Positivity: positivity of rapid HIV testing (number of HIV-positive case found out of total number of persons tested) at nearby health facilities.

Cost_facility: average cost per facility-based HIV testing session at nearby health facilities.

Price_level: proxy for input price level variation across countries based on per capita GDP.

$\beta_{0}$ : model intercept.

$\beta_{1}-\beta_{13}$ : model coefficients computed using empirical dataset.

$\mathrm{Q}_{\mathrm{k}}$ : quantity of units for level k: number of HIVST kits distributed.

Using the model to predict costs at scale in Lesotho

Coefficients in a log-linear model are the estimated percentage change-elasticity-in the dependent variable for a unit change in the independent variable. ${ }^{4142}$ We used the 'predict' function in R package to estimate average cost for various scale values. We used exponential function to back transform estimated average costs as our error terms were normally distributed. ${ }^{43}$ We compared total costs at 'national' (all five districts) and district level to allow for comparison between observed costs (scale-up periods 1, 2 and 3) and predicted costs. The likelihood ratio test (LRT), comparing the goodness of fit of two statistical models, was used to assess whether we could simplify the model (ie, reduce the number of parameters in our regression model) for cost projections.

\section{Patient and public involvement}

To conduct our costing study from a provider perspective, it was not appropriate to involve patients or the public in the design, or conduct, or reporting, or dissemination plans of our research.

\section{Ethical approvals}

The trials are registered under the Clinical Trials Network (ClinicalTrials. gov) under registration numbers NCT02793804, NCT02718274 and Pan African clinical trials registry PACTR201607001701788 for Malawi, Zambia and Zimbabwe. Informed consent was obtained from all individual participants included in the time and motion study.

\section{RESULTS}

\section{Descriptive statistics}

Descriptive statistics (mean, SD, min and max) of data are presented for the full sample and for each country in table 3. Sample mean of average cost per kit distributed was $\$ 14.58$ (median: \$13.54). On average, each site had 26 (range: 2-272) distributors and distributed 993 (range: 160-5904) kits. Part of the strategy was to reach men, and those who had never tested before, these groups made up, on average, $48 \%$ and $12 \%$, respectively, of kit recipients. Average distance of site to warehouse was 162 $\mathrm{km}$, population size of 672429 inhabitants and, finally, positivity rate of $8 \%$ and the cost of provider-delivered HIV testing was $\$ 6.22$ per person tested at nearby health facilities.

\section{Determinants of HIVST average costs at programme level and model simplification}

We retained a combination of three scale variables, normally distributed, quadratic and cubic, because they explained the largest share of the variance $\left(R^{2}\right.$ was the highest). ${ }^{44}$ We explored several functional forms for other cost determinants; only efficiency was logtransformed as it improved model fit. Other determinants were kept with a normal distribution. The correlation matrix showed high correlation between population and scale, between distributors and campaign style, and low or no correlation otherwise (online supplemental appendix figure S1); therefore, the variables population and distributors were excluded. Multicollinearity was assessed on the remaining cost drivers using the variance inflation factor (VIF) test and was acceptable (mean VIF: 2.94). We tested 


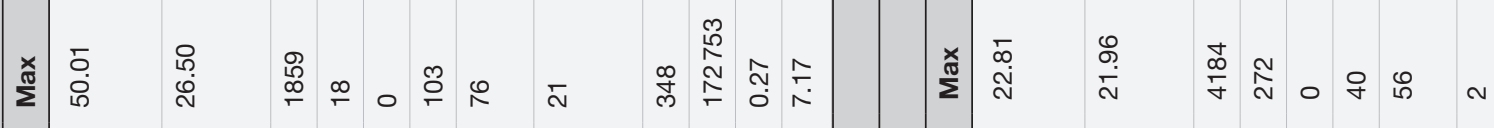

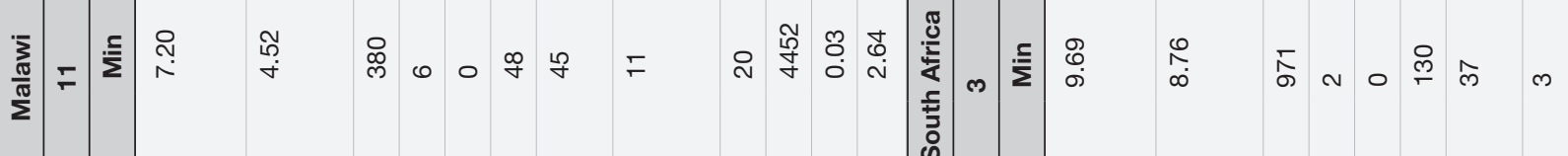

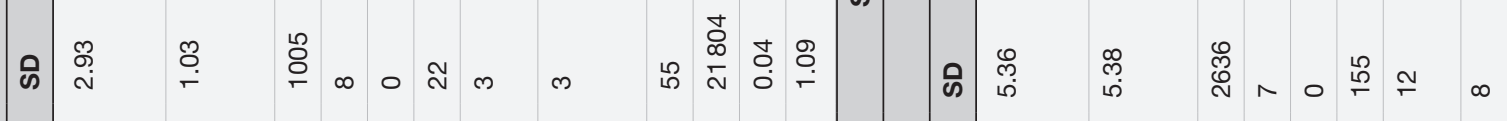

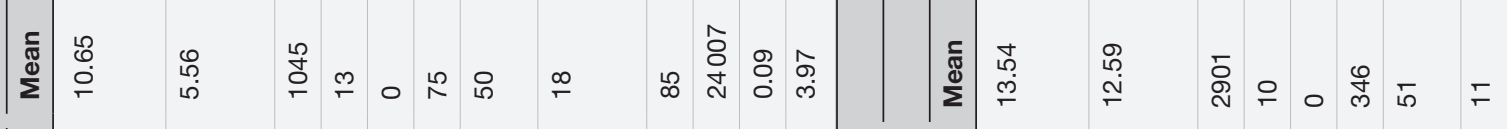

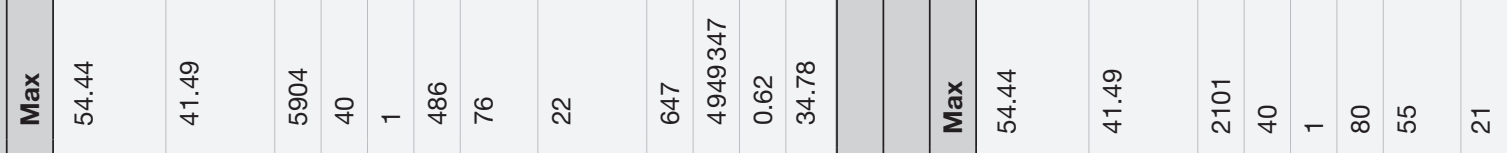

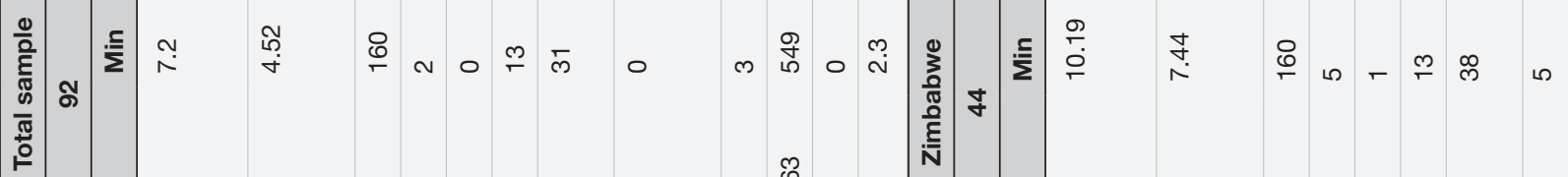

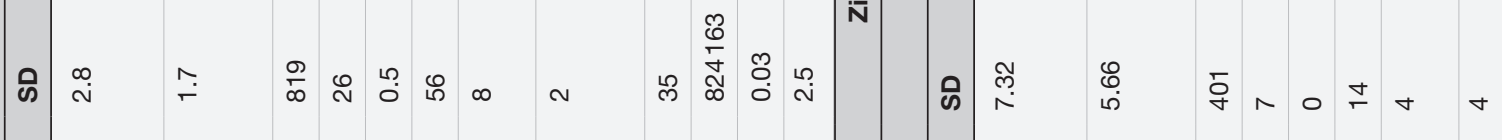

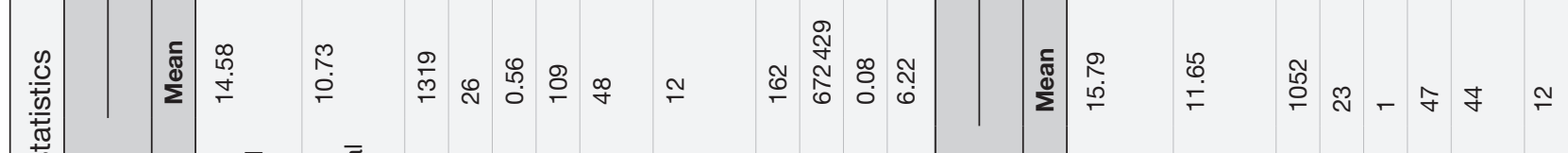

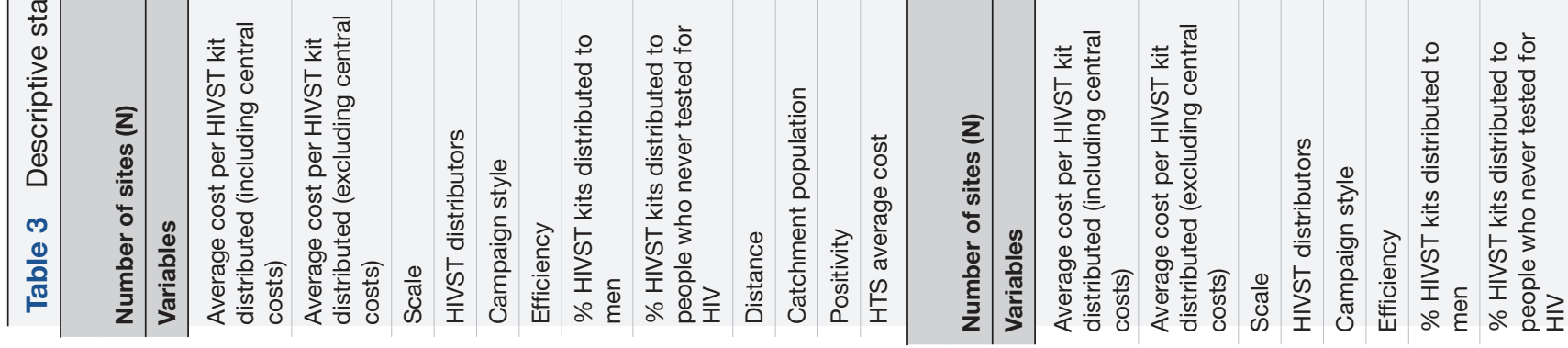




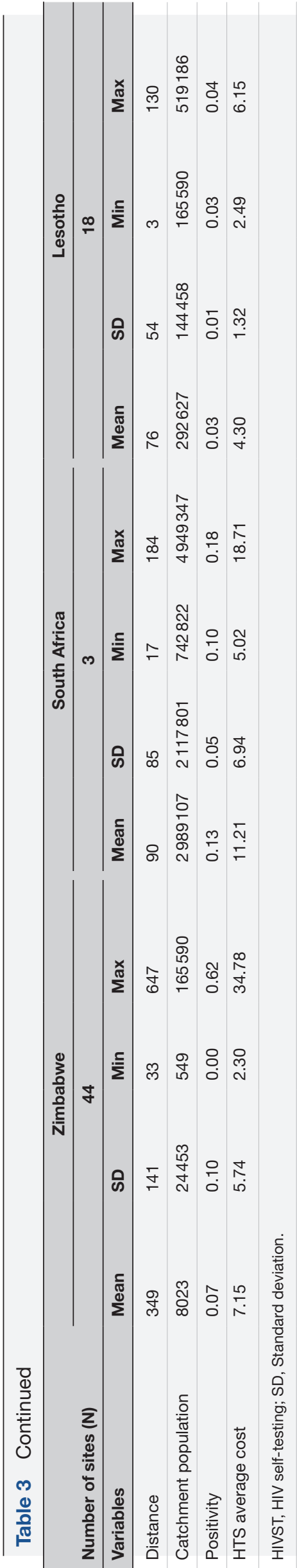

for heteroscedasticity using the Breusch-Pagan test and failed to reject the null hypothesis $(p>0.05)$; therefore, heteroscedasticity was not present in the model.

We progressively added cost determinants to our model starting with scale, followed by organisational characteristics, characteristics of the population reached, environmental factors and price level (table 4). Major cost determinants were scale, campaign-style distribution, \% of kits distributed to men, distance from the implementer's warehouse and price level (model 5). We found a negative association between scale and average cost. If scale increases by 100 HIVST kits distributed, average cost decreases by $0.16 \%$. Campaign-style distribution increased costs by $19 \%$. An increase in $1 \%$ of kits distributed to men increased average cost by $0.67 \%$. An increase of the distance between the implementer's warehouse and HIVST distribution areas by $1 \mathrm{~km}$ increased costs by $0.01 \%$. Finally, an increase of per capita GDP (price_level) by $\$ 10$ led to an increase of average cost by $0.01 \%$.

For the model simplification analysis, we removed $\%$ never tested, positivity and HTS costs at health facility in model 6, as these determinants were not significant (table 5). Model 5 did not significantly improve fit to the data than Model 6 (LRT: p value: 0.82). Additionally, model 7, where efficiency was removed, did not significantly reduced goodness of fit than model 6 (LRT: p value: 0.67 ).

\section{Observed costs at scale in Lesotho}

The cost analysis (online supplemental appendix table S2) was conducted for each of the three costing periods at national and district levels. The main cost drivers identified were personnel costs at national level ( $9 \%, 12 \%$ and $9 \%$ for periods 1,2 and 3 respectively), district level $(29 \%, 29 \%$ and $31 \%)$ and community outreach $(27 \%, 28 \%$ and $21 \%)$, as well as HIVST kits costs $(25 \%, 20 \%$ and $30 \%)$. Overall, HIVST distribution volumes were decreasing between periods 1 and 2 (14 099 and 12471 kits), then increasing between periods 2 and 3 (12 471 and 25106 kits). Between districts, we observed wide variation in HIVST kit distribution volumes ranging from 1130 kits (Mohale's Hoek, period 2) to 7958 kits (Leribe, period 3). At national level, average cost per kit distributed varied between periods: $\$ 10.69, \$ 13.71$ and $\$ 9.12$ in periods 1, 2 and 3, respectively. At district level, wide variation was observed with average cost ranging from $\$ 6.97$ (Leribe, period 3) to $\$ 22.81$ (Berea, period 2).

\section{Predicting costs at scale in Lesotho using the ECF with varying levels of complexity and comparison with observed costs at scale}

We present observed total costs for each scale-up period at national and district level in Lesotho, against projected costs from models 5-7 (figure 2). Overall cost projections at given scale were close to observed costs at district level and at national level in period 1, whereas we report some discrepancies at national level in periods 2 and 3. The 


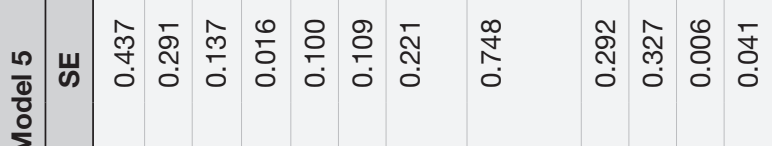

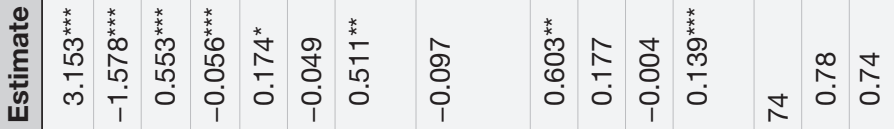

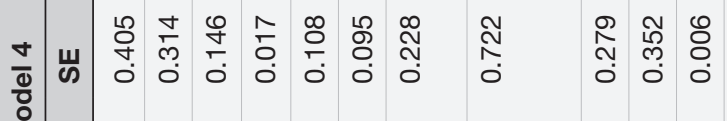

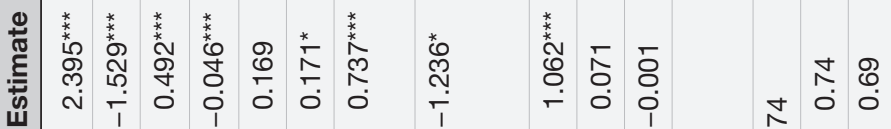

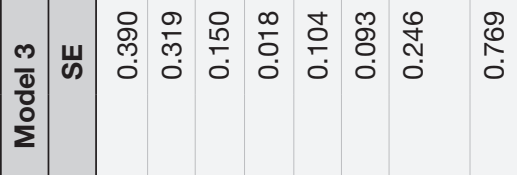

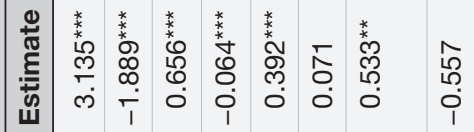

\begin{tabular}{lll}
5 & 0 \\
\hdashline & 0 & 0 \\
0
\end{tabular}

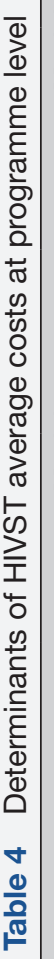

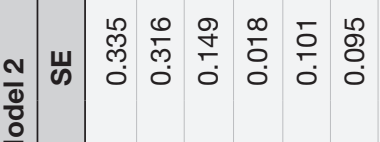

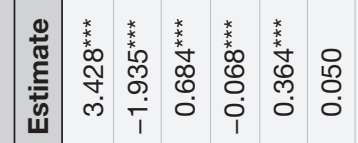

T

$\frac{\text { m }}{c}$

$\frac{\Omega}{0}$

깅

$\stackrel{\stackrel{2}{F}}{\vec{F}}$

$\stackrel{\vec{F}}{\stackrel{3}{0}}$

음

बे

क

$\vec{\circ}$

峁

$\frac{3}{30}$

กิ

ठ̀े

음

产

足

망

о

$\stackrel{2}{\Phi}$

웅

言

응

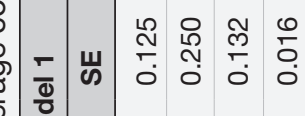

$\Sigma$

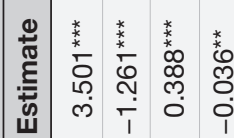

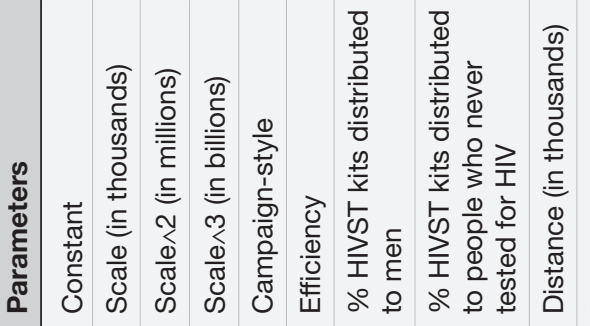

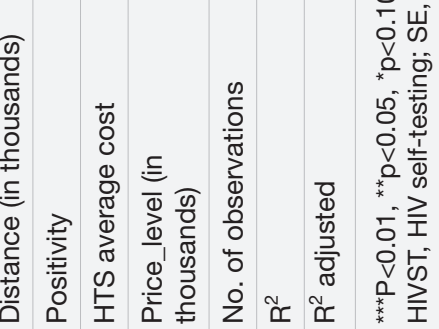


Table 5 Model simplification approach

\begin{tabular}{|c|c|c|c|c|c|c|}
\hline \multirow[b]{2}{*}{ Parameters } & \multicolumn{2}{|c|}{ Model 5} & \multicolumn{2}{|c|}{ Model 6} & \multicolumn{2}{|c|}{ Model 7} \\
\hline & Estimate & SE & Estimate & SE & Estimate & SE \\
\hline Constant & $3.153^{\star \star \star}$ & 0.437 & $3.110^{\star \star \star}$ & 0.418 & $2.963^{\star \star \star}$ & 0.191 \\
\hline Scale (in thousands) & $-1.578^{\star \star \star}$ & 0.291 & $-1.630^{\star \star \star}$ & 0.271 & $-1.662^{\star \star \star}$ & 0.257 \\
\hline Scale^2 (in millions) & $0.553^{\star \star \star}$ & 0.137 & $0.575^{\star \star \star}$ & 0.129 & $0.585^{\star \star \star}$ & 0.126 \\
\hline Scale $\wedge 3$ (in billions) & $-0.056^{\star \star \star}$ & 0.016 & $-0.059^{\star \star \star}$ & 0.015 & $-0.060^{\star \star *}$ & 0.015 \\
\hline Campaign style & $0.174^{\star}$ & 0.100 & $0.187^{\star \star}$ & 0.093 & $0.205^{\star \star}$ & 0.080 \\
\hline Efficiency & -0.049 & 0.109 & -0.037 & 0.092 & & \\
\hline \% HIVST kits distributed to men & $0.511^{\star \star}$ & 0.221 & $0.519^{* *}$ & 0.216 & $0.542^{\star *}$ & 0.208 \\
\hline $\begin{array}{l}\% \text { HIVST kits distributed to people } \\
\text { who never tested for HIV }\end{array}$ & -0.097 & 0.748 & & & & \\
\hline Distance (in thousands) & $0.603^{* *}$ & 0.292 & $0.582^{\star *}$ & 0.245 & $0.623^{\star \star \star}$ & 0.222 \\
\hline Positivity & 0.177 & 0.327 & & & & \\
\hline HTS average cost & -0.004 & 0.006 & & & & \\
\hline Price_level (in thousands) & $0.139^{\star \star *}$ & 0.041 & $0.133^{\star \star *}$ & 0.035 & $0.126^{\star \star \star}$ & 0.029 \\
\hline No. of obs. & 74 & & 74 & & 74 & \\
\hline $\mathrm{R}^{2}$ & 0.78 & & 0.77 & & 0.77 & \\
\hline $\mathrm{R}^{2}$ adjusted & 0.74 & & 0.75 & & 0.75 & \\
\hline \multicolumn{7}{|c|}{ Likelihood ratio test: model 5 versus model 6 , and model 6 versus model 7} \\
\hline $\begin{array}{l}\text { Difference of } \chi^{2} \text { values } \\
\text { (df) }\end{array}$ & & & $0.93(3)$ & & $0.18(1)$ & \\
\hline$P$ value & & & 0.82 & & 0.67 & \\
\hline
\end{tabular}

comparison of projected total costs also showed that more parsimonious ECF ( model 7) were not less accurate than more data hungry ECF (model 5). Simplified models were more precise due to narrower $95 \%$ CIs but would sometimes not include the observed costs in their range ( model 5 vs model 7: all districts - period 2).

\section{DISCUSSION}

Our study developed an econometric cost function for scaling up community-based HIVST programmes for the general population in Southern Africa, using data from five countries. Our results suggest that programme design characteristics, including the scale of HIVST

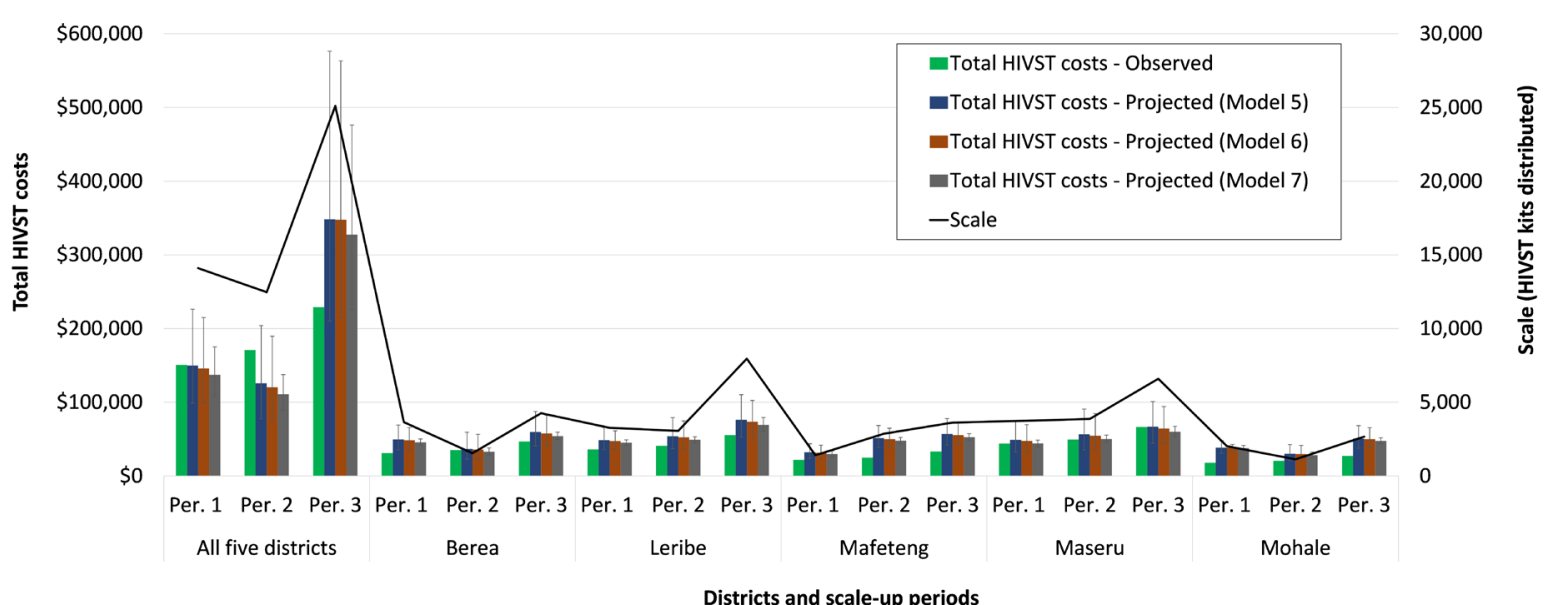

Figure 2 National and district level observed and projected (models 5-7) HIVST total costs by scale-up period in Lesotho (error bars: 95\% Cls). HIVST, HIV self-testing. 
distribution, type of community-based intervention, characteristics of the population targeted with HIVST (men), distance from implementer's headquarter and per capita GDP can be used to predict average costs. These findings are consistent with previous studies on HIV prevention cost functions highlighting the role of scale as the major cost determinant among other cost drivers. ${ }^{35} 363946$ We also found that reaching men was associated with higher average HIVST distribution costs. Previous studies have shown that men's uptake of community HIV testing is often lower than uptake in women, as men are less likely to be present when mobile testing teams visit households, or might be more reluctant to take a kit, therefore increasing provision costs. ${ }^{5748}$ In addition, it is increasingly relevant to account for decreasing returns to scale for epidemics such as HIV or malaria where testing efforts have increased over decades, making it more expensive to reach the last percentage of the target population, due to the last remaining untested living in remote areas, or being part of harder to reach population groups.

Our model simplification approach showed that we could use a more parsimonious model to predict costs without significantly losing accuracy. This is particularly relevant as in most studies, we have scant opportunity to collect large amounts of location-specific cost data, and the necessary background information (eg, percentage of population who never tested at the community level) might not exist. The per capita GDP variable showed that our cost function could potentially be applied to other countries. This is in line with the study by Cerecero-García and colleagues ${ }^{49}$ that used per capita GDP as a determinant to predict HIV treatment average costs in out-of-sample countries. The extrapolation of cost projections to other Southern African countries seems possible with our parsimonious empirical cost function; however, it would probably require additional or different variables in other settings such as in West Africa.

The use of ECF to predict costs at scale in the context of financial planning and budgeting is limited in the development economics literature. ${ }^{14} 185051$ In a study from 2018, Berman and colleagues ${ }^{18}$ used a combination of ECF and ACF (using the normative costing approach incorporated in the WHO's OneHealth tool) to provide low and high estimates of financial needs to plan Ethiopia's primary healthcare system. The authors suggested that ECF could provide a low estimate of resource needs due to limited inclusion of capital investments, future changes in services offered to meet changes in health needs and future improvements potentially required for the quality of services provided. Their findings suggest that our cost projections based on ECF could potentially underestimate the amount of resources needed.

Our findings in Lesotho for the observed cost analysis across scale-up periods are consistent, in terms of average costs and cost composition, with the existing literature on HIVST costs in the region, ranging from
US $\$ 8.15$ per kit distributed in Malawi to US $\$ 16.42$ in Zambia. ${ }^{12} 19$ This suggests that they can be used as comparators with forecast costs analysis. Overall, ECF gave highly accurate and consistent scale-up cost estimates compared with observed costs at district level, suggesting a good predictive capacity of our empirical cost function. At higher scale (national level), cost predictions were close to observed costs in period 1 but were slightly below observed costs in period 2 and above in period 3. HIVST implementation and scale-up in Lesotho went through varying levels of efficiency (ie, number of HIVST kits distributed by agents monthly) and was explained by an HIVST implementation strategy maturing over time with important impact on programme costs. ${ }^{19}$ HIVST scale-up went through an inefficient phase in period 2 with limited HIVST distribution volumes because of the time spent by providers to offer individual onsite counselling and supervision for self-testing at the mobile outreach. Period 2 was then followed by a more efficient phase, when selftesting booth were introduced at the mobile outreach (period 3) allowing staff to supervise onsite self-testing of many clients at the same time. Although we account for efficiency as a cost determinant in our models 5-7, it was not significant, maybe related to our relatively small sample size or the small role that distributor salaries play in overall costs. Additionally, our ECF is highly sensitive to scale (strongest cost driver), explained by observed large economies of scale in our country sample (Malawi, Zambia and Zimbabwe), ${ }^{12}$ which is why the 'efficiency' effect is only observed at larger scale (national and not district level). Consequently, during the inefficient period 2, our projected costs are underestimating observed costs (predicting higher economies of scale than actually observed) and vice versa in period 3 .

Our study has several limitations. First, although we use primary data and standardised cost data collection and analysis methods, we have an unbalanced sample of sites. While some countries contributed with a large sample of sites, others only included a few observations. We assume that because the same implementer (PSI) is working in the region with similar financial reporting system, this unbalance would not affect our modelling approach. Second, we use an observed scale-up period in Lesotho that evolved over time as programme matures, limiting our assessment of cost projections' accuracy. Third, we do not have country-specific panel data; therefore, time-dependent unobserved cost determinants are ignored for the econometric analysis. Fourth, while these estimates provide some likely key drivers of costs and their direction, we do expect our cost projections to be more accurate within settings where the main change relates to variations in scale. Fifth, our cost analysis is limited to average costs per kit distributed as the private nature of the HIVST did not allow us to estimate the costs of identifying new HIVpositive individuals or those HIV-positive individuals 
linked to treatment through HIVST, limiting the applications of our findings by policymakers and programme planners.

Our empirical analysis adds to the discussion on the trade-off between simplicity versus accuracy in cost projection method. Further research should estimate health intervention costs at scale using the three different cost function methods (SCM, ECF and ACF) and compare cost predictions at various scales, ultimately to inform the choice of a cost projection method based on the intended use of the cost estimates.

\section{Author affiliations \\ ${ }^{1}$ Department of Global Health and Development, London School of Hygiene \& Tropical Medicine, London, UK \\ ${ }^{2}$ Department of HIV/AIDS \& TB, Malawi-Liverpool-Wellcome Trust Clinical Research Programme, Blantyre, Malawi \\ ${ }^{3}$ Zambart, Lusaka, Zambia \\ ${ }^{4}$ Department of Health Economics, Centre for Sexual Health HIV/AIDS Research, Harare, Zimbabwe \\ ${ }^{5}$ Global HIV, Hepatitis and STI Programme, World Health Organisation, Geneva, Switzerland \\ ${ }^{6}$ MRC International Statistics and Epidemiology Group, London School of Hygiene \& Tropical Medicine, London, UK \\ ${ }^{7}$ Population Services International, Washington, DC, USA \\ ${ }^{8}$ Department of Clinical Research, London School of Hygiene \& Tropical Medicine, London, UK \\ ${ }^{9}$ Department of Internal Medicine, Health Economics and Epidemiology Research Office (HE2R0) - University of the Witwatersrand, Johannesburg, South Africa \\ ${ }^{10}$ Center for Global Health and Development, Boston University, Boston, \\ Massachusetts, USA \\ ${ }^{11}$ Department of Global Health \& Development, Joint United Nations Programme on HIV/AIDS, Geneva, Switzerland}

Twitter Collin Mangenah @cmangenah01 and Cheryl Johnson @ccasejohn

Acknowledgements The study was undertaken in collaboration with Unitaid, Population Services International, WHO and the HIV Self-Testing Africa Research Consortium institutions. The authors would like to thank all their partners and study participants in Malawi, Zambia, Zimbabwe, South Africa, and Lesotho.

Contributors Md'E and FT-P designed the study. Md'E coordinated, conducted data analysis and wrote the paper. LAS, LM and CM conducted data collection/ analysis. GBG, GM-R, GFM, MN, CJ, KH and ELC provided logistical support and intellectual inputs. All authors revised the manuscript and agreed for publication.

Funding This work was supported by the Unitaid/PSI HIV Self-Testing Africa (STAR) Project, grant number P0 \# 8477-0-600.

Disclaimer Sanofi Pasteur did not provide funding for this work and had no role in study design, data collection, data analysis, data interpretation or writing of the report.

Competing interests GBG is currently employed by Sanofi Pasteur, France.

Patient consent for publication Not required.

Ethics approval Ethical approvals for the parent studies were obtained from the Medical Research Council of Zimbabwe, Malawi College of Medicine Research Ethics Committee, University of Zambia Biomedical Research Ethics Committee, London School of Hygiene \& Tropical Medicine Ethics Committee and University College London Ethics Committee.Ethical approval was obtained from the National Health Research Ethics Committee of Lesotho and the London School of Hygiene \& Tropical Medicine Ethics Committee (Ref. \# ID64-2018 and 14887, respectively). Ethics approvals for the costing work in South Africa were obtained from research ethics committees of the London School of Hygiene \& Tropical Medicine (Ref. \# 15408), the Human Research Ethics Committee (Medical) of the University of Witwatersrand (Ref. \# M180379) and the Institutional Review Board of Boston University School of Public Health (Ref. \# H-37713).

Provenance and peer review Not commissioned; externally peer reviewed.

Data availability statement Data are available on request. NA.
Supplemental material This content has been supplied by the author(s). It has not been vetted by BMJ Publishing Group Limited (BMJ) and may not have been peer-reviewed. Any opinions or recommendations discussed are solely those of the author(s) and are not endorsed by BMJ. BMJ disclaims all liability and responsibility arising from any reliance placed on the content. Where the content includes any translated material, BMJ does not warrant the accuracy and reliability of the translations (including but not limited to local regulations, clinical guidelines, terminology, drug names and drug dosages), and is not responsible for any error and/or omissions arising from translation and adaptation or otherwise.

Open access This is an open access article distributed under the terms of the Creative Commons Attribution IGO License (CC BY NC 3.0 IGO), which permits use, distribution,and reproduction in any medium, provided the original work is properly cited. In any reproduction of this article there should not be any suggestion that WHO or this article endorse any specific organization or products. The use of the WHO logo is not permitted. This notice should be preserved along with the article's original URL.

Disclaimer: The author is a staff member of the World Health Organization. The author alone is responsible for the views expressed in this publication and they do not necessarily represent the views, decisions or policies of the World Health Organization.

\section{ORCID iDs}

Linda Alinafe Sande http://orcid.org/0000-0002-4246-5338

Collin Mangenah http://orcid.org/0000-0002-0733-0622

Melissa Neuman http://orcid.org/0000-0002-8870-6504

\section{REFERENCES}

1 The Joint United Nation Programme on HIV and AIDS. Global AIDS update, 2018.

2 Johnson CC, Kennedy C, Fonner V, et al. Examining the effects of HIV self-testing compared to standard HIV testing services: a systematic review and meta-analysis. J Int AIDS Soc 2017;20:21594.

3 World Health Organization. Guidelines on HIV self-testing and partner notification - supplement to consolidated Guidelines on HIV testing Services, 2016.

4 London School of Hygiene and Tropical Medicine. UNITAID/PSI HIV Self-Testing Africa (StAR) - research, 2018.

5 Hatzold K, Gudukeya S, Mutseta MN, et al. HIV self-testing: breaking the barriers to uptake of testing among men and adolescents in sub-Saharan Africa, experiences from STAR demonstration projects in Malawi, Zambia and Zimbabwe. J Int AIDS Soc 2019;22:e25244.

6 Choko AT, MacPherson P, Webb EL, et al. Uptake, accuracy, safety, and linkage into care over two years of promoting annual SelfTesting for HIV in Blantyre, Malawi: a community-based prospective study. PLoS Med 2015;12:e1001873.

7 d'Elbée M, Indravudh PP, Mwenge L, et al. Preferences for linkage to HIV care services following a reactive self-test: discrete choice experiments in Malawi and Zambia. AIDS 2018;32:2043-9.

8 Indravudh PP, Sibanda EL, d'Elbée M, et al. 'I will choose when to test, where I want to test': investigating young people's preferences for HIV self-testing in Malawi and Zimbabwe. AIDS 2017;31:S203-12.

9 Mulubwa C, Hensen B, Phiri MM, et al. Community based distribution of oral HIV self-testing kits in Zambia: a clusterrandomised trial nested in four HPTN 071 (PopART) intervention communities. Lancet HIV 2019;6:e81-e92.

10 Sibanda EL, d'Elbée M, Maringwa G, et al. Applying user preferences to optimize the contribution of HIV self-testing to reaching the "first 90" target of UNAIDS Fast-track strategy: results from discrete choice experiments in Zimbabwe. J Int AIDS Soc 2019;22:e25245.

11 Sande L, Maheswaran H, Mangenah C, et al. Costs of accessing HIV testing services among rural Malawi communities. AIDS Care 2018;30:27-36

12 Mangenah C, Mwenge L, Sande L, et al. Economic cost analysis of door-to-door community-based distribution of HIV self-test kits in Malawi, Zambia and Zimbabwe. J Int AIDS Soc 2019;22:e25255.

13 Ministry of Health of Lesotho. National HIV testing strategy of lesotho - period 2018 - 2023, 2018.

14 d'Elbée M, Gomez GB, Griffiths U. Estimating health care costs at scale: a review of cost function applications in low- and middleincome countries, 2020.

15 Vassall A, Sweeney S, Kahn J, et al. Reference case for estimating the costs of global health services and interventions, 2017. 
16 Meyer-Rath G, Over M. HIV treatment as prevention: modelling the cost of antiretroviral treatment--state of the art and future directions. PLoS Med 2012;9:e1001247.

17 Sloman J, Garratt D, Guest J. Economics. 10 edn. Pearson Education Limited, 2018.

18 Berman P, Mann C, Ricculli M-L. Can Ethiopia finance the continued development of its primary health care system if external resources decline? Health Syst Reform 2018;4:227-38.

19 d'Elbée M, Makhetha MC, Jubilee M, et al. Using HIV self-testing to increase the affordability of community-based HIV testing services. AIDS 2020;34:2115-23.

20 Jamieson L, Johnson L, Matsimela K, et al. The cost effectiveness and optimal configuration of HIV self-test distribution in South Africa: a model analysis. BMJ Glob Health 2021.

21 Terris-Prestholt F, Santos A, Sweeney S, et al. The rapid syphilis test toolkit implementation 1: guidelines for cost effectiveness analysis of syphilis screening strategies, 2011.

22 Cunnama L, Sinanovic E, Ramma L, et al. Using top-down and bottom-up costing approaches in LMICs: the case for using both to assess the incremental costs of new technologies at scale. Health Econ 2016;25:53-66.

23 Sande LA, Matsimela K, Mwenge L. Costs of integrating HIV SelfTesting in public health facilities in Malawi, South Africa, Zambia and Zimbabwe. BMJ Glob Health 2021.

24 Mwenge L, Sande L, Mangenah C, et al. Costs of facilitybased HIV testing in Malawi, Zambia and Zimbabwe. PLoS One 2017; 12:e0185740.

25 Hutton G, Baltussen R. Valuation of goods in cost-effectiveness analysis: notions of opportunity costs and transferability across time and countries. In: World Health organization global programme on evidence for health policy discussion paper. Geneva, 2003.

26 Mihaylova B, Briggs A, O'Hagan A, et al. Review of statistical methods for analysing healthcare resources and costs. Health Econ 2011;20:897-916.

27 Bautista-Arredondo S, La Hera-Fuentes G, Contreras-Loya D, et al. Efficiency of HIV services in Nigeria: determinants of unit cost variation of HIV counseling and testing and prevention of mother-to-child transmission interventions. PLoS One 2018;13:e0201706.

28 Chandrashekar S, Guinness L, Kumaranayake L, et al. The effects of scale on the costs of targeted HIV prevention interventions among female and male sex workers, men who have sex with men and transgenders in India. Sex Transm Infect 2010;86:i89-94.

29 Dandona L, Kumar SP, Ramesh Y, et al. Changing cost of HIV interventions in the context of scaling-up in India. AIDS 2008:22:S43-9.

30 Dandona L, Sisodia P, Prasad TLN, et al. Cost and efficiency of public sector sexually transmitted infection clinics in Andhra Pradesh, India. BMC Health Serv Res 2005;5:69.

31 Galárraga O, Wamai RG, Sosa-Rubí SG, et al. Hiv prevention costs and their predictors: evidence from the ORPHEA project in Kenya. Health Policy Plan 2017;32:1407-16.

32 Guinness L, Kumaranayake L, Hanson K. A cost function for HIV prevention services: is there a 'u' - shape? Cost Eff Resour Alloc 2007;5:13.

33 Guinness L, Kumaranayake L, Rajaraman B, et al. Does scale matter? the costs of HIV-prevention interventions for commercial sex workers in India. Bull World Health Organ 2005;83:747-55.

34 Kumar SGP, Dandona R, Schneider JA, et al. Outputs and cost of HIV prevention programmes for truck drivers in Andhra Pradesh, India. BMC Health Serv Res 2009;9:82.

35 Lépine A, Chandrashekar S, Shetty G, et al. What determines HIV prevention costs at scale? Evidence from the Avahan programme in India. Health Econ 2016;25:67-82.

36 Marseille E, Giganti MJ, Mwango A, et al. Taking art to scale: determinants of the cost and cost-effectiveness of antiretroviral therapy in 45 clinical sites in Zambia. PLoS One 2012;7:e51993.
37 Menzies NA, Berruti AA, Blandford JM. The determinants of HIV treatment costs in resource limited settings. PLoS One 2012;7:e48726.

38 Obure CD, Guinness L, Sweeney S, et al. Does integration of HIV and $\mathrm{SrH}$ services achieve economies of scale and scope in practice? A cost function analysis of the Integra initiative. Sex Transm Infect 2016:92:130-4.

39 Siapka M, Remme M, Obure CD, et al. Is there scope for cost savings and efficiency gains in HIV services? A systematic review of the evidence from low- and middle-income countries. Bull World Health Organ 2014;92:499-511AD.

40 Zeileis A, Hothorn T. Diagnostic checking in regression relationships. $R$ News 2002;2:7-10.

41 UCLA: Statistical Consulting Group. FAQ: how do I interpret a regression model when some variables are log transformed? 2020.

42 Wooldridge JM. Introductory econometrics: a modern approach (upper level economics titles). Nashville, T ATN: Southwestern College Publishing, 2012: 41. 673-90.

43 Bardsen G, Lutkepohl H. Forecasting levels of log variables in vectors autoregressions. European University Institute - Department of Economics, 2009.

44 Lave JR, Lave LB. Hospital cost functions. Annu Rev Public Health 1984:5:379-95

45 Vitaliano DF. On the estimation of hospital cost functions. $J$ Health Econ 1987;6:305-18.

46 Dandona L, Sisodia P, Kumar SGP, et al. HIV prevention programmes for female sex workers in Andhra Pradesh, India: outputs, cost and efficiency. BMC Public Health 2005;5:98.

47 Johnson LF, van Rensburg C, Govathson C, et al. Optimal HIV testing strategies for South Africa: a model-based evaluation of population-level impact and cost-effectiveness. Sci Rep 2019;9:12621.

48 Sharma M, Ying R, Tarr G, et al. Systematic review and metaanalysis of community and facility-based HIV testing to address linkage to care gaps in sub-Saharan Africa. Nature 2015;528:S77-85.

49 Cerecero-García D, Pineda-Antunez C, Alexander L, et al. A metaanalysis approach for estimating average unit costs for art using pooled facility-level primary data from African countries. Afr J AIDS Res 2019;18:297-305.

50 Castro V. Pure, white and Deadly... expensive: a bitter sweetness in health care expenditure. Health Econ 2017;26:1644-66.

51 Global Burden of Disease Health Financing Collaborator Network. Trends in future health financing and coverage: future health spending and universal health coverage in 188 countries, 2016-40. Lancet 2018;391:1783-98.

52 Bank W. GDP per capita (current US\$) - all countries and economies, 2019.

53 Zimbabwe National Statistics Agency, ICF International. Zimbabwe demographic and health survey 2015: final report. Rockville, Maryland, USA: Zimbabwe National Statistics Agency (ZIMSTAT) and ICF International, 2016.

54 Population-based HIV Impact Assessments (PHIA). Lesotho population-based HIV impact assessment (LePHIA), 2017.

55 National Statistical Office/Malawi, ICF. Malawi demographic and health survey 2015-16. Zomba, Malawi: National Statistical Office and ICF, 2017.

56 Central Statistical Office/Zambia, Ministry of Health/Zambia, University of Zambia Teaching Hospital Virology Laboratory, University of Zambia Department of Population Studies, Tropical Diseases Research Centre/Zambia, ICF International. Zambia demographic and health survey 2013-14. Rockville, Maryland: USA: Central Statistical Office/Zambia, Ministry of Health/Zambia, and ICF International, 2015

57 UNAIDS. Global AIDS update, 2019.

58 London School of Hygiene and Tropical Medicine. UNITAID/PSI HIV Self-Testing Africa (StAR) - research protocols, 2018. 